\title{
RADIOCARBON DATING THE EXPLOITATION PHASES OF THE GROTTA DELLA MONACA CAVE IN CALABRIA, SOUTHERN ITALY: A PREHISTORIC MINE FOR THE EXTRACTION OF IRON AND COPPER
}

\author{
Gianluca Quarta ${ }^{1,2} \bullet$ Felice Larocca $^{3}$ Marisa D’Elia ${ }^{1}$ - Valentina Gaballo ${ }^{1}$ Maria Macchia $^{1} \bullet$ \\ Giuseppe Palestra ${ }^{1}$ Lucio Calcagnile $^{1}$
}

\begin{abstract}
Grotta della Monaca is a karstic cave in Calabria (southern Italy) that plays an important role in reconstructing the oldest strategies for the acquisition of mineral resources in the Mediterranean. In fact, systematic archaeological excavations carried out by the University of Bari allowed the identification of intense prehistoric mining activities aimed at the exploitation of iron and copper ores. Archaeological evidence suggests different phases of frequentation of the cave spanning from the Upper Paleolithic, Neolithic, Copper and Bronze ages up to the Middle Ages. In order to establish an absolute timeframe for the different phases, a radiocarbon dating campaign was carried out and the results presented in this paper.
\end{abstract}

\section{INTRODUCTION}

Since 2000, a research mission of the University of Bari has been investigating, in collaboration with the Italian Ministry of Cultural Heritage, Soprintendenza per i Beni Archeologici of Calabria, an underground cave of great archaeological interest in the northwestern region of Calabria (Figure 1). Known since the 19th century, the cave has been the object of repeated speleological explorations mainly after World War II.
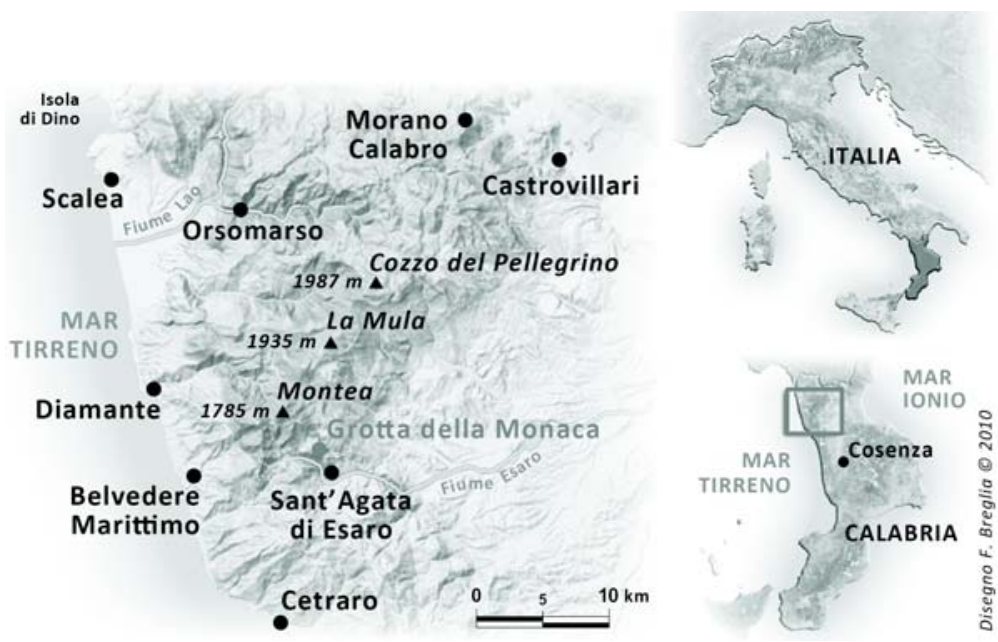

Figure 1 Site location

The cave, called Grotta della Monaca, is characterized by a majestic entrance (600 m asl) dominating the upper valley of the Esaro River (Figure 2). Extending for $355 \mathrm{~m}$ in triassic dolomitic limestone, the cave is formed by various places characterized by different volumes and morphologies (galleries, chambers, narrow passages) (Figure 3) and contains abundant mineralization of iron

${ }^{1}$ CEDAD-Department of Engineering for Innovation, University of Salento, via per Monteroni, 73100 Lecce, Italy.

${ }^{2}$ Corresponding author. Email: gianluca.quarta@unisalento.it.

${ }^{3}$ Centro Regionale di Speleologia “Enzo dei Medici,” via Lucania 3, Roseto Capo Spulico (CS), Italy.

(c) 2013 by the Arizona Board of Regents on behalf of the University of Arizona

Proceedings of the 21st International Radiocarbon Conference edited by A J T Jull \& C Hatté

RADIOCARBON, Vol 55, Nr 2-3, 2013, p 1246-1251 


\section{G Quarta et al.}

(limonite, lepicocrocite, goethite, hematite, yukonite) and, in smaller amounts, of copper (malachite, azurite, brochantite, libethenite, sampleite) (Dimuccio et al. 2005). These mineral resources have strongly conditioned the human usage as the cave was used since prehistory for the exploitation of both iron and copper minerals (Larocca 2010, 2012).

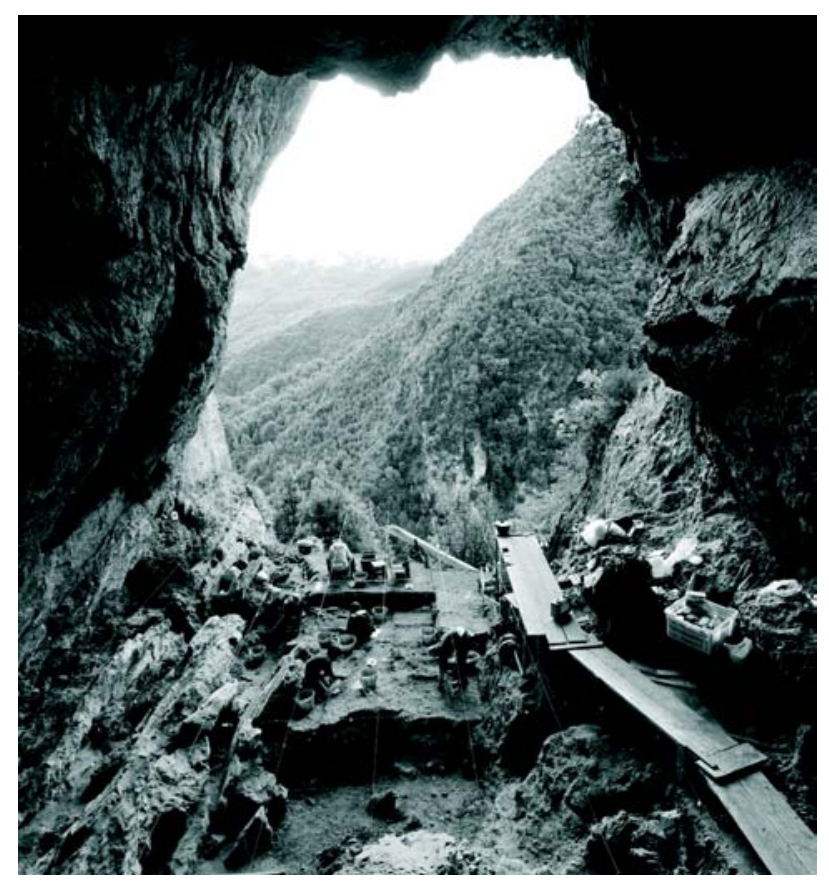

Figure 2 Entrance of the cave during the archaeological excavations

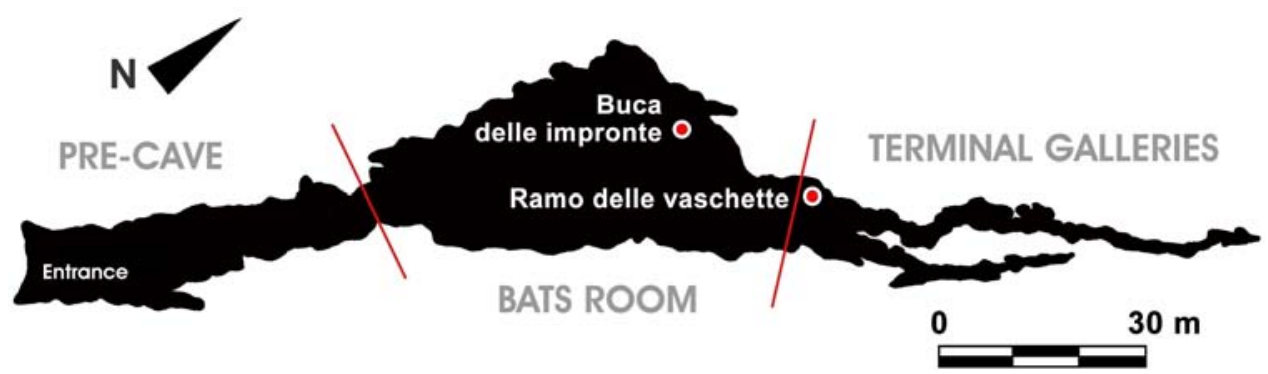

Figure 3 General cavity plan (red lines mark the 3 main cave sectors: pre-cave; Bats' room; Terminal galleries)

The exploitation of iron minerals is mainly related to the extraction iron oxides and hydroxides like goethite. Archaeological evidence suggests that goethite mining episodically started already in the Upper Paleolithic and intensified during the Neolithic and the Copper Age (Larocca 2010). These extractive activities are archaeologically testified by hundreds of digging traces still visible in the cave deposits, characteristic of the use of bone tools.

The extraction of goethite overlaps, during the 4th millennium BC, with the exploitation of copper minerals, mainly malachite. This second mining phase is characterized by the use of new tools, now made of stone, but which do not seem to completely replace the bone-made ones. The prehistoric 
${ }^{14}$ C Dating Exploitation Phases of Grotta Della Monaca

extractive activities in the Grotta della Monaca stopped during the Bronze Age, when the inner sectors of the cavity, previously used for the exploitation of iron and copper, started to be used for funeral purposes, as testified by the remains of $\sim 30$ buried individuals. Mining mainly of iron minerals in the galleries of the initial part of the cave resumed much later in the Medieval period, and carried out using metallic tools.

Radiocarbon dating analyses were conducted at the CEDAD (Centre for Dating and Diagnostics), Department of Engineering for Innovation, University of Salento, Italy, in order to define the overall framework of the various stages of frequentation based of the archaeological evidence. The definition of a clear chronological framework is usually difficult in paleo-mine contexts mainly because of the lack of clear stratigraphies to be used as reference. Archaeological excavations allow essentially to identify the final and most recent extractive activities, which, in most of the cases, strongly disturb or even completely delete the testimonies related to the more ancient exploitation activities. Furthermore, in the case of Grotta della Monaca, the coexistence of both mining and funeral activities in the same areas makes it significantly more difficult to identify, and thus understand, the dynamics related to human presence. In this objectively complex situation, ${ }^{14} \mathrm{C}$ dating presented a fundamental contribution to the distinction and functional identification of the different phases related to the human frequentation of the cave.

\section{SAMPLE SELECTION AND METHODS}

Twenty-four charcoal and bone samples were selected and analyzed for this study as summarized in Table 1 . The samples were chosen in different areas of the cave corresponding to the different occupation/exploitation phases as identified based on archaeological excavations (Table 1). Both chemical processing and accelerator mass spectrometry (AMS) ${ }^{14} \mathrm{C}$ dating were carried out at CEDAD (Calcagnile et al. 2004).

Charcoal samples were pretreated with the standard acid-alkali-acid (AAA) protocol used at CEDAD (D’Elia et al. 2004), while collagen extraction of bone samples followed the Longin protocol (Longin 1971). Purified sample material was then combusted to carbon dioxide at $900{ }^{\circ} \mathrm{C}$ in a sealed quartz tube together with copper oxide and silver wool (D’Elia et al. 2004). The released $\mathrm{CO}_{2}$ was reduced at $600{ }^{\circ} \mathrm{C}$ to graphite by using $\mathrm{H}_{2}$ as reducing agent and iron powder as catalyst. The graphite-iron powder mixture was then pressed in the aluminum target holder of the sputtering ion source of the AMS system where ${ }^{14} \mathrm{C} /{ }^{12} \mathrm{C}$ and ${ }^{13} \mathrm{C} /{ }^{12} \mathrm{C}$ ratios were measured. Measured ${ }^{14} \mathrm{C} /{ }^{12} \mathrm{C}$ ratios were then corrected for isotopic mass fractionation by using the $\delta^{13} \mathrm{C}$ term measured with the accelerator and for sample processing and machine background (Calcagnile at al. 2005).

\section{RESULTS AND DISCUSSION}

${ }^{14} \mathrm{C}$ dating results are summarized in Table 1 as conventional ${ }^{14} \mathrm{C}$ ages, which were then calibrated into calendar years by using OxCal v 4 software (Bronk Ramsey 2009) and IntCal09 data (Reimer et al. 2009). Results of calibration are shown in Figures 4 and 5. The analysis of the ${ }^{14} \mathrm{C}$ data allow to immediately confirm the long "life" of the cave spanning from the Paleolithic to the Middle Ages.

Determining the oldest phase of frequentation of the cave was obtained through ${ }^{14} \mathrm{C}$ analysis of the sample LTL3580A, a human ulna intentionally put under a large calcareous boulder likely for ritual purposes. The sample was dated to $16,761 \pm 100 \mathrm{BP}(18,285-17,621 \mathrm{cal} \mathrm{BC})$ corresponding to the Upper Paleolithic (Figure 4).

${ }^{14} \mathrm{C}$ dating of charcoal samples taken from residues of wooden torches found in the 2 branches called Buca delle impronte and Ramo delle vaschette (Figure 3) enabled identifying the most intense 


\section{G Quarta et al.}

Table 1 Summary of the analyzed samples, the laboratory codes, the archaeological phase and the measured conventional ${ }^{14} \mathrm{C}$ age.

\begin{tabular}{lllc}
\hline Sample ID & Material & Archaeological phase & ${ }^{14} \mathrm{C}$ age \\
\hline LTL3580A & Human ulna & Paleolithic & $16,761 \pm 100 \mathrm{BP}$ \\
LTL3587A & Charcoal & Neolithic/Copper Age & $5827 \pm 55 \mathrm{BP}$ \\
LTL5395A & Charcoal & & $5247 \pm 45 \mathrm{BP}$ \\
LTL3588A & Charcoal & $5245 \pm 50 \mathrm{BP}$ \\
LTL5092A & Charcoal & $5216 \pm 45 \mathrm{BP}$ \\
LTL5093A & Charcoal & $5194 \pm 45 \mathrm{BP}$ \\
LTL3583A & Charcoal & $5183 \pm 50 \mathrm{BP}$ \\
LTL3584A & Charcoal & $5010 \pm 50 \mathrm{BP}$ \\
LTL5396A & Charcoal & & $5002 \pm 55 \mathrm{BP}$ \\
LTL3582A & Charcoal & & $4935 \pm 45 \mathrm{BP}$ \\
LTL3581A & Charcoal & & $4880 \pm 45 \mathrm{BP}$ \\
LTL3579A & Goat horn & $4684 \pm 50 \mathrm{BP}$ \\
LTL5089A & Bone & Bronze Age & $3308 \pm 50 \mathrm{BP}$ \\
LTL5090A & Bone & & $3270 \pm 45 \mathrm{BP}$ \\
LTL5085A & Bone & & $3263 \pm 45 \mathrm{BP}$ \\
LTL5088A & Bone & & $3247 \pm 45 \mathrm{BP}$ \\
LTL5084A & Bone & & $3204 \pm 45 \mathrm{BP}$ \\
LTL5087A & Bone & & $3192 \pm 45 \mathrm{BP}$ \\
LTL5091A & Charcoal & & $3111 \pm 50 \mathrm{BP}$ \\
LTL5393A & Charcoal & & $700 \pm 35 \mathrm{BP}$ \\
LTL3586A & Charcoal & Medieval & $618 \pm 45 \mathrm{BP}$ \\
LTL3585A & Charcoal & & $580 \pm 45 \mathrm{BP}$ \\
LTL5394A & Charcoal & & $568 \pm 40 \mathrm{BP}$ \\
LTL5094A & Charcoal & &
\end{tabular}

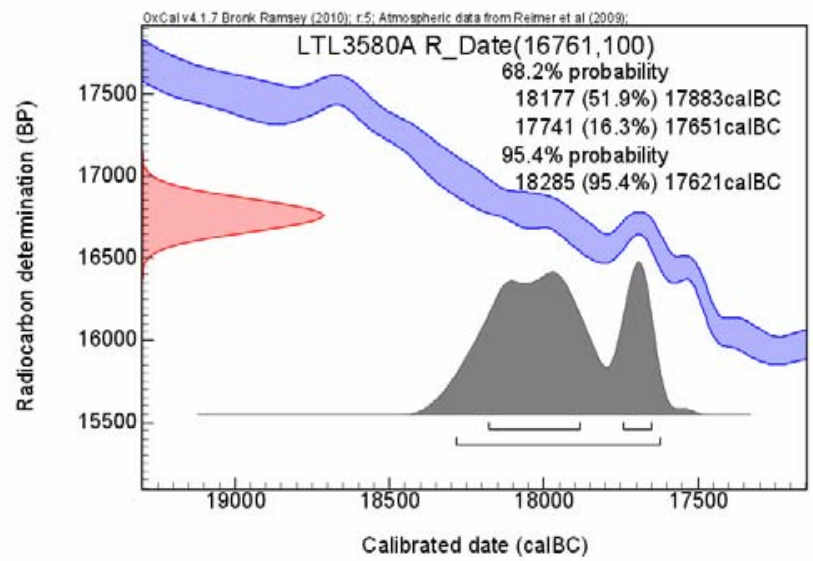

Figure 4 Calibration of the conventional ${ }^{14} \mathrm{C}$ age of sample LTL3580A

period of exploitation of the cave mainly for iron minerals from the second half of the 5th millennium BC to the first half of the 4th millennium BC (Figure 5). In the most remote sector of the cave, a goat horn (sample LTL3579A), probably used as a tool and then abandoned after it was broken, assigns the last prehistoric mining of the cave to 3640-3360 cal BC. 


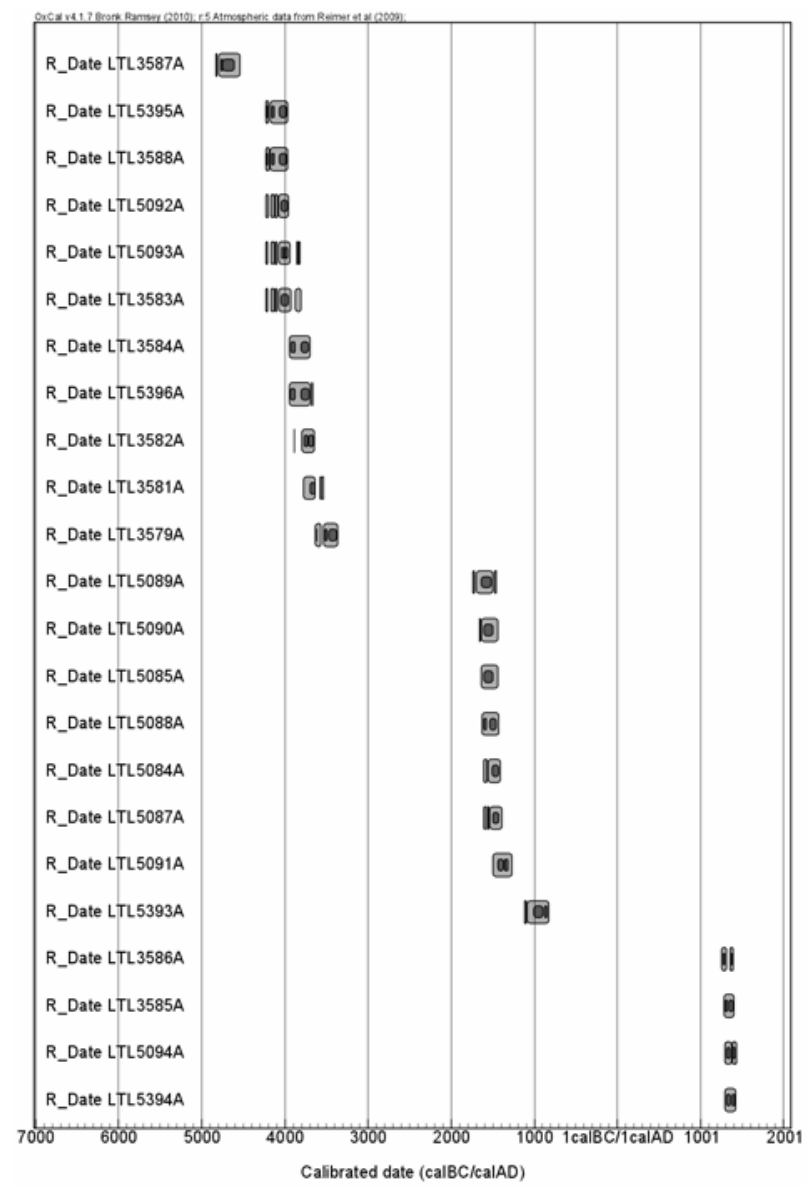

Figure 5 Calibrated ${ }^{14} \mathrm{C}$ ages of the analyzed samples

About 2000 yr later, after the end of the mining activities, the cave was used for funeral purposes as testified by different human remains that were all dated to the 2nd millennium BC (Bronze Age). After this period, a gap in the frequentation of the cave is observed until the Late Middle Ages as shown by the ${ }^{14} \mathrm{C}$ dating results obtained on 4 samples all dated to the period between the 12th and the 13th centuries $\mathrm{AD}$.

\section{CONCLUSIONS}

${ }^{14} \mathrm{C}$ dating performed on both charcoal and bone samples selected from different areas of the Grotta della Monaca Cave, allowed to absolutely date the different occupation/exploitation phases of this site. The results highlighted the presence of a Paleolithic burial and to establish that the most intense period of exploitation of the mineral resources of the cave spanned about $1000 \mathrm{yr}$ from the Late Neolithic to the beginning of the Copper Age. The analysis of bones from the burials indicates that this site was used as a hypogean burial ground during the 2nd millennium BC. The last use of the cave for mining activities is also documented during the Middle Ages by the results obtained on 4 charcoal samples. 


\section{G Quarta et al.}

\section{REFERENCES}

Bronk Ramsey C. 2009. Bayesian analysis of radiocarbon dates. Radiocarbon 51(1):337-60.

Calcagnile L, Quarta G, D’Elia M, Rizzo A, Gottdang A, Klein M, Mous DJW. 2004. A new accelerator mass spectrometry facility in Lecce, Italy. Nuclear Instruments and Methods in Physics Research B 223-224: 16-20.

Calcagnile L, Quarta G, D’Elia M. 2005. High resolution accelerator-based mass spectrometry: precision, accuracy and background. Applied Radiation and Isotopes 62(4):623-9.

D’Elia M, Calcagnile L, Quarta G, Rizzo A, Sanapo C, Laudisa M, Toma U, Rizzo A. 2004. Sample preparation and blank values at the AMS radiocarbon facility of the University of Lecce. Nuclear Instruments and Methods in Physics Research B 223-224:278-83.

Dimuccio LA, Garavelli A, Pinto D, Vurro F. 2005. Le risorse minerarie. In: Larocca $\mathrm{F}$, editor. La miniera pre-protostorica di Grotta della Monaca (Sant'Agata di Esaro - Cosenza). Edizioni Centro Regionale di Speleologia “Enzo dei Medici.” p 37-41.

Larocca F, editor. 2005. La miniera pre-protostorica di Grotta della Monaca (Sant'Agata di Esaro Cosenza). Edizioni Centro Regionale di Speleologia "Enzo dei Medici."

Larocca F. 2010. Grotta della Monaca: a prehistoric copper and iron mine in the Calabria region (Italy). In:
Anreiter P, Goldenberg G, Hanke K, Krause R, Leitner W, Mathis F, Nicolussi K, Oeggl K, Pernicka E, Prast M, Schibler J, Schneider I, Stadler H, Stöllner T, Tomedi G, Tropper P, editors. Mining in European History and its Impact on Environment and Human Societies. Proceedings for the 1st Mining in European History Conference of the SFB-HIMAT (Innsbruck, 12-15 November 2009). Innsbruck: Innsbruck University Press. p 267-70.

Larocca F. 2012. Grotta della Monaca (Calabria, Italia meridionale). Una miniera neolitica per l'estrazione dell'ocra. In: Borrell M, Bosch J, Clop X, Molist M, editors. Xarxes al Neolitic. Actes Congrés Internacional (Gavà/Bellaterra, 2-4 February 2011). Rubricatum, Revista del Museu de Gavà 5:249-56.

Longin R. 1971. New method of collagen extraction for radiocarbon dating. Nature 230(5291):241-2.

Reimer PJ, Baillie MGL, Bard E, Bayliss A, Beck JW, Blackwell PG, Bronk Ramsey C, Buck CE, Burr GS, Edwards RL, Friedrich M, Grootes PM, Guilderson TP, Hajdas I, Heaton T, Hogg AG, Hughen KA, Kaiser KF, Kromer B, McCormac FG, Manning SW, Reimer RW, Richards DA, Southon JR, Talamo S, Turney CSM, van der Plicht J, Weyhenmeyer CE. 2009. IntCal09 and Marine09 radiocarbon age calibration curves, 0-50,000 years cal BP. Radiocarbon 51(4): 1111-50. 